\title{
PEMANFAATAN LIMBAH ORGANIK RUMAH TANGGA DALAM PEMBUATAN PUPUK BOKASHI DI KELURAHAN TUAH KARYA, KECAMATAN TAMPAN, PEKANBARU
}

\author{
Novia Gesriantuti*, Elsie, Israwati Harahap, Nofripa Herlina, Yeeri Badrun \\ Prodi Biologi, Fakultas MIPA dan Kesehatan \\ *email: noviagesriantuti@umri.ac.id
}

\begin{abstract}
Abstrak
Limbah organik rumah tangga yang dihasilkan cukup banyak dan belum dimanfaatkan, maka perlu upaya pemanfaataan limbah organik rumah tangga secara tepat agar tidak menimbulkan masalah bagi lingkungan sekitarnya. Penanganan limbah organik rumah tangga yang baik dapat mengurangi dampak lingkungan sekaligus membantu mengatasi masalah pemenuhan kebutuhan pupuk organik. Oleh karena itu langkah awal yang perlu dilakukan adalah bagaimana mengolah limbah organik rumah tangga untuk menghasilkan starter/EM dan pupuk bokashi serta meningkatkan keterampilan masyarakat Kelurahan Tuah Karya dalam mengolah limbah organik rumah tangga yang nantinya bisa dimanfaatkan oleh masyarakat sebagai pupuk bagi tanaman dalam polybag/pot yang mereka tanam.
\end{abstract}

Kata kunci: Limbah organik rumah tangga, Starter/EM, pupuk bokashi

\section{PENDAHULUAN}

Kota Pekanbaru merupakan salah satu Kota di Indonesia yang memiliki jumlah penduduk tahun 2013 sebanyak 999.031 jiwa. Dalam satu dekade terakhir, laju pertumbuhan penduduk Kota Pekanbaru sebesar 4,06 persen (BPS, 2014). Seiring meningkatnya jumlah penduduk Kota Pekanbaru akan berpengaruh terhadap daya dukung dan daya tamping lingkungan, termasuk di lingkungan rumah tangga. Di lingkungan rumah tangga dihasilkan limbah organik maupun limbah an organik bahkan di tempat kerja/kantor maupun tempat-tempat umum lainnya sering dijumpai sampah sebagai benda yang tidak digunakan lagi.

Limbah organik apabila tidak dikelola dengan baik akan menimbulkan pencemaran lingkungan dan gangguan kesehatan terutama bagi masyarakat yang berada di sekitar sampah tersebut. Seperti yang kita ketahui limbah organik yang menumpuk akan membusuk dan mengeluarkan aroma yang tidak sedap, sehingga mengundang berbagai vektor penyakit seperti lalat, nyamuk, tikus dan kecoa. Selain itu limbah yang dibuang sembarangan, misalnya ke selokan atau sungai akan menghambat aliran air. Akibatnya limbah tersebut bertumpuk sehingga aliran air tersumbat dan akan mengakibatkan banjir. Namun, tidak semua limbah itu tidak berguna. Beberapa jenis limbah organik masih dapat diolah sehingga memiliki nilai ekonomis. Salah satu bentuk pengelolaan limbah organik adalah pembuatan pupuk organik yang dapat mengurangi masalah limbah sekaligus menciptakan nilai ekonomi dari limbah, salah satu jenis pupuk organik yang telah popular adalah Bokashi. 


$\begin{array}{lr}\text { Bokashi adalah pupuk } & \text { kompos } \\ \text { yang dihasilkan dari proses } \\ \text { fermentasi bahan organik } & \text { dengan } \\ \text { memanfaatkan limbah } & \text { organik } \\ \text { rumah tangga. Bahan untuk }\end{array}$
pembuatan bokashi dapat diperoleh dengan mudah disekitar perumahan, pasar, lahan pertanian, seperti sisa sayuran, buah-buahan, rumput, tanaman kacang-kacangan, sekam, pupuk kandang atau serbuk gergaji.

Kelurahan Tuah Karya merupakan salah satu kelurahan yang ada pada wilayah Kecamatan Tampan Kota Pekanbaru, dan posisi geografisnya terletak pada sebelah barat dari Kota Pekanbaru yang berbatasan langsung dengan Kabupaten Kampar. Kelurahan Tuah Karya memeiliki luas $12.085 \mathrm{~km} 2$, dengan jumlah RW sebanyak $14 \mathrm{RW}$ dan RT sebanyak 93. Jumlah penduduk di Kelurahan Tuah Karya berkisar 40.723 jiwa, jumlah penduduk Laki-laki 20.100 orang dan Perempuan sebanyak 20.623 orang dengan kepadatan penduduk 3.157 Per/Km2.

Sebagian masyarakat Kelurahan Tuah Karya belum melakukan pengolahan limbah rumah tangga, karena kurangnya pengetahuan tentang pengolahan limbah rumah tangga yang baik. Oleh karena itu untuk mengubah kebiasaan membuang limbah organik menjadi mengelola limbah, perlu upaya yang dimulai secara individualdi setiap rumah.

Berdasarkan data yang diperoleh dapat dilihat bahwa tingkat pekerjaan masyarakat pemukiman di Kelurahan Tauh Karya berada pada kategori sedang. Ini menunjukkan kalau ratarata masyarakat di sana memiliki pekerjaan tingkat menengah dimana dalam penelitian ini yang termasuk pada kategori menengah ialah petani, pedagang (berjualan), PNS, buruh dan karyawan swasta.

Pada saat sekarang dengan tingginya harga cabe, mendorong masyarakat di Kelurahan Tuah Karya khususnya RW $10 \quad$ RT 03 yang menanam cabe dan sayuran lainnya dalam polybag. Namun masih ada kendala berupa pertumbuhan tanaman yang kurang baik serta adanya serangan penyakit dan hama. Berdasarkan permasalahan diatas, maka penulis tertarik untuk melakukan penyuluhan dengan judul Pemanfaatan Limbah Organik Rumah Tangga dalam Pembuatan Pupuk Bokashi di Kelurahan Tuah Karya, KecamatanTampan, Pekanbaru.

Tujuan dilakukannya kegiatan ini adalah meningkatkan kepedulian masyarakat Kelurahan Tuah Karya, Kecamatan Tampan terhadap keikut sertaan menjaga kualitas lingkungan hidup yang sehat dan bersih melalui pengelolaan sampah limbah rumah tangga menjadi pupuk bokashi.

\section{METODE PENGABDIAN}

Pelaksanaan kegiatan ini berupa pelatihan kepada masyarakat untuk memanfaatkan sampah rumah tangga menjadi pupuk bokashi. Kegiatan tersebut sebagai berikut:

\section{Pengumpulan Limbah Organik}

Untuk melaksanakan program ini, limbah organik rumah tangga diperoleh dari warga Kelurahan Tuah Karya RT 03/ RW 10.

\section{Pembuatan larutan Starter / EM (Efektif Microorganism)}


ISSN : 2550-0198

Untuk membuat pupuk bokashi, terlebih dahulu dibuat larutan starter/EM sebagai bahan pencampur pada limbah organik yang akan dijadikan pupuk bokashi. Hal-hal yang dipersiapkan adalah alat, bahan yang terkait dalam pembuatan larutan starter/EM serta penjabaran cara pembuatan larutan starter/EM. Adapun langkah-langkah pembuatan starter/EM adalah :

- Disiapkan bahan-bahan berikut: limbah sayuran, buah-buahan beserta kulitnya

- Semua bahan dicampur, dicacah dan dilumatkan dengan blender.

- Bahan-bahan tersebut dimasukkan ke dalam ember yang ada penutupnya,lalu ditambahkan air, gula pasir dan air kelapa.

- Diaduk perlahan hingga merata, kemudian ember ditutup rapat, didiamkan selama7 hari.

- Setelah 7 hari akan terbentuk cairan berwarna coklat, disaring cairan tersebut, air hasil saringan merupakan larutan starter/EM yang bisa dijadikan dekomposer pupuk bokashi.

- Cairan disimpan dalam wadah. Larutan starter/EM bisa dipakai hingga 6 bulan, sedangkan ampasnya bisa digunakan sebagai kompos.

\section{Pembuatan Pupuk Bokashi}

Langkah-langkah pembuatan pupuk bokashi adalah:

- Disiapkan bahan-bahan berikut: sisa sayuran, buah-buahan, sisa makanan (nasi, roti dan lain-lain), tulang ayam,sekam atau dedak, kotoran ternak, arang sekam,tanah humus, jerami atau serasah dan gula pasir.

- Sampah organik dicacah menjadi potongan kecil,dicampurkan dengan sekam/dedakdan arang sekam.

- Bahan-bahan tersebut dimasukkan ke dalam ember yang ada penutupnya, lalu ditambahkan dedak/serbuk gergaji dan arang sekam

- Aduk dengan membolak-balik tanah dengan cangkul agar semua bahan tercampur.

- Larutan starter/EM diencerkan dengan air, ditambahkan gula pasir. Kemudian disiramkan pada campuran bahan baku tadi.

- Setelah tercampur diambil sedikit adonan segenggam dan kepalkan dengan tangan, apabila tidak buyar maka adonan sudah siap difermentasi.

- Ditutup rapat.

- Agar suhu adonan tidak terlalu panas karena fermentasi, diaduk adonan setiap hari sehingga suhu bisa dipertahankan pada kisaran $40^{\circ}-50^{\circ} \mathrm{C}$.

- Dibiarkan selama 2minggu, setelah 2minggu pupuk bokashi sudah jadi dan siap digunakan sebagai pupuk.

\section{Aplikasi Pupuk Bokashi Pada}

Tanaman dalam Polybag / PotWarga Dilakukan pemberian pupuk bokashi bagi warga dan akan digunakan pada tanaman polybag/pot.

\section{HASIL DAN PEMBAHASAN}

Penyuluhan dan praktik langsung pembuatan starter (cairan mikroorganisme) dan pupuk organik berbahan dasar sampah organik telah dilaksanakan di rumah Posyandu, Kelurahan Tuah Karya pada hari Sabtu tanggal 01 Apri 2017, dihadiri oleh kira-kira 20 orang ibu-ibu rumah tangga dari RT 03/RW 10. 
Kegiatan ini diawali dengan pemaparan (metode ceramah singkat) dilanjutkan dengan diskusi dan terakhir praktik langsung tentang pembuatan dan pemberian sampel starter dan pupuk organik.

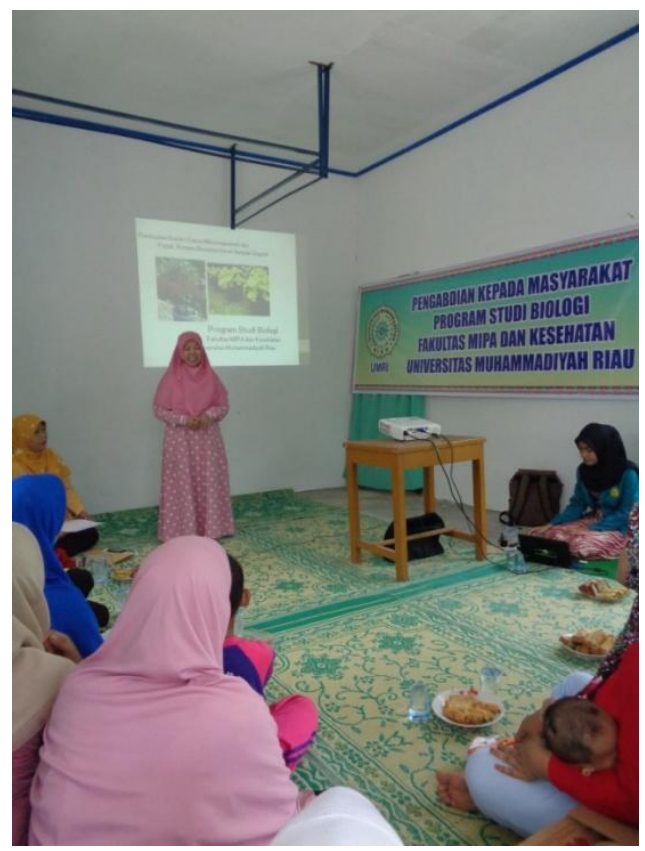

Gambar 1. Pemaparan tentang pembuatan Starter/EM dan Pupuk bokashi

Pada saat diskusi, peserta banyak bertanya tentang bahanbahan yang bisa digunakan dalam pembuatan starter dan pupuk organik. Mereka sangat tertarik untuk mengetahui semuanya karena selama ini belum tahu tentang sampah atau sisa-sisa sayuran segar, buah-buahan dan makanan yang bisa dimanfaatkan untuk pembuatan pupuk organik. Biasanya sampah langsung dibuang ke tempat sampah. Pertanyaan lain yang banyak dibahas adalah tentang manfaat dari pupuk organik. Hasil diskusi menunjukkan ketertarikan dari peserta untuk mencoba membuat pupuk organik secara mandiri agar sampah atau sisa-sisa sayuran segar dan buahbuahan tidak lagi menjadi sampah. Nantinya pupuk akan mereka manfaatkan untuk pupuk tanaman cabe dalam polybag.

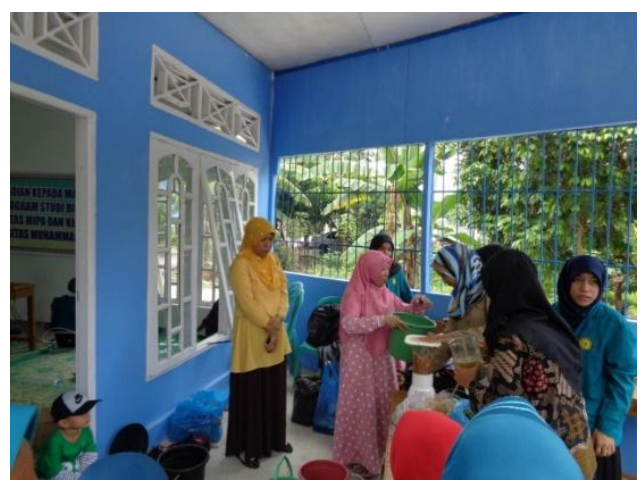

Gambar 2. Praktik langsung pembuatan Starter/EM dan pupuk bokashi

Dilihat dari tujuan kegiatan pegabdian masyarakat yang dilakukan yaitu meningkatkan pemahaman masyarakat tentang pemanfaatan sampah organik sebagai bahan baku membuat starter dan pupuk organik dan pemanfaatan pupuk organik sebagai pupuk tanaman dalam polybag atau pot, maka dapat dikatakan bahwa tujuan kegiatan ini tercapai. Terbukti dengan banyak pertanyaan yang diajukan para peserta dan melebihi dari waktu yang ditargetkan. Peserta sangat antusias dan serius dalam mengikuti kegiatan. Dari evaluasi selama kegiatan, para peserta menjadi memiliki pemahaman lebih baik tentang pemanfaatan sampah organik yang berasal dari dapur. Para peserta mengetahui tentang manfaat dan keuntungan menggunakan pupuk organik bagi tanaman dalam polybag/pot.

Setelah 7 hari, dilakukan pengecekan hasil dari praktik langsung ternyata fermentasi menghasilkan starter yang cukup 
ISSN : 2550-0198

baik. Hal ini dapat diketahui dari warna cairan yang dihasilkan berwarna coklat dan beraroma menyegarkan (Gambar 4.3).

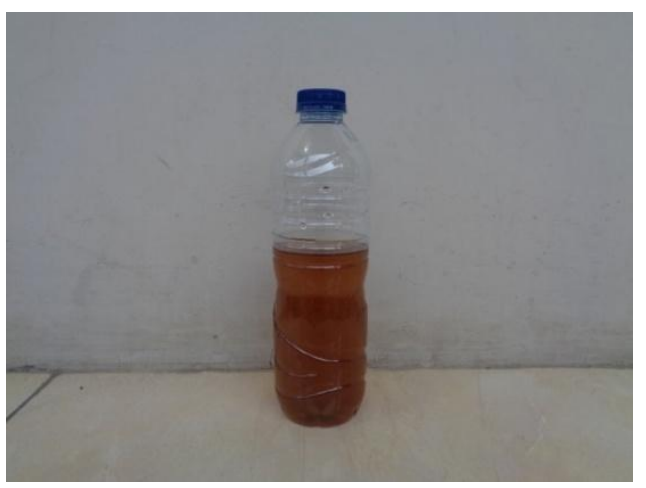

Gambar. 3. Starter/EM (Cairan Mikroorganisme)

Kemudian setelah 15 hari dilakukan pengecekan terhadap hasil pengomposan pupuk bokashi, pupuk yang dihasilkan telah berwarna coklat dan mengeluarkan bau seperti tanah yang menandakan bahwa pengomposan berhasil (Gambar 4.4). Hasil praktik langsung tersebut dibagi-bagikan kepada masyarakat untuk dimanfaatkan.

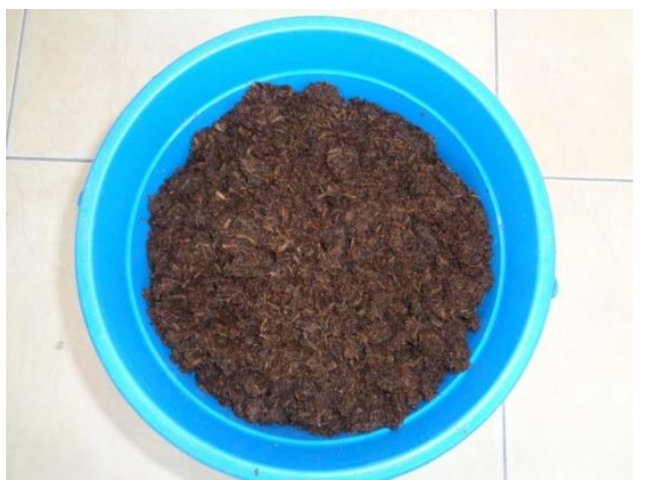

Gambar 4. Pupuk Bokashi

\section{SIMPULAN}

1. Kegiatan penyuluhan tentang pemanfaatan limbah organik rumah tangga dalam pembuatan starter dan pupuk Bokashi di Kelurahan Tuah
Karya, Kecamatan Tampan, Pekanbaru telah berhasil dilakukan sesuai dengan perencanaan sebelumnya.

2. Para peserta memiliki pemahaman yang lebih baik tentang pemanfaatan limbah organik rumah tangga dalam pembuatan starter dan pupuk Bokashi.

3. Para peserta berminat untuk membuat starter dan pupuk bokashi secara mandiri dan memanfaatkannya untuk tanaman dalam polybag atau pot.

\section{UCAPAN TERIMAKASIH}

Terima kasih kami ucapkan kepada Universitas Muhammadiyah Riau (UMRI) sebagai pemberi dana, Ketua RW 10 dan Ketua RT 03, masyarakat di Kelurahan Tuah Karya, Pekanbaru dan mahasiswa Prodi Biologi, FMIPA\&Kesehatan, UMRI atas bantuan dan kerjasamanya sehingga terselenggaranya pengabdian masyarakat ini.

\section{DAFTAR PUSTAKA}

[1] ........... Cara Membuat Pupuk Bokashi. www.alamtani.com. Diakses 20 Januari 2017.

[2] .............EM4 Pertanian. www.em4-indonesia.com. Diakses 20 Januari 2017.

[3] ............Penggunaan Pupuk Bokashi dengan Teknologi EM (Effective Microorganisms). Himagro Faperta Universitas Padjajaran. Diakses 20 Januari 2017.

[4] Prasojo, S. 2012. Memupuk Uang Dari Sampah. Penerbit Bestari. Jakarta 
[5] Muzayyanah. 2009. Pengaruh Pemberian Pupuk Bokashi Terhadap Pertumbuhan Tanaman Sawi (Brassica juncea L.). Program Studi Biologi. Universitas Islam Negeri Maulana Malik Ibrahim. Malang.

[6] Zainuddin Z., 2016. Cara Membuat Pupuk Bokashi. Portal Agrotani Indonesia. Diakses 20 Januari 2017. 